\title{
Финансовые механизмы обеспечения интенсификации инновационного производства
}

\author{
Ваганова O.B. ${ }^{17}$
}

В статье рассматриваются финансовые методы и механизмы обеспечения региональной инновачионной инфраструктуры. Финансовая составляющуая инновационной инфраструктуры является одним из основных механизмов интенсификации инновационной деятельности. Именно на реализачию механизмов финансирования инновационного производства ложится основная часть активизации инновационного потенциала региона.

\section{$J E L: R 150$}

Ключевые слова: регион, инновачионная инфраструктура, инновационный прочесс, финансовая инфраструктура

В настоящее время актуальным стало развитие тех направлений научных исследований, в которых главной переменной выбраны институты и происходящие в них изменения. Одной из причин выбора и успешного развития этого направления стал опыт стран с высокими темпами экономического роста, во многом обусловленными наличием развитых институциональных структур: открытым режимом предпринимательства, частной собственностью, интенсивным использованием факторов производства, макроэкономической стабильностью и устойчивой политической системой.Усиление внимания к теоретическому исследованию проблем инновационной деятельности вызвано и тем, что идет напряженная работа по органичному вхождению российской экономики в мировое хозяйство. Преодоление технического отставания России практически во всех отраслях промышленности предполагает усиление инновационного характера производственной деятельности, формирование особой инновационной сферы с присущими ей спецификой и субъектами. Существует сопряженность процессов интенсификации инновационного производства на различных уровнях управления. Поэтому необходимо разрешить и ряд общеэкономических проблем интенсификации инновационного производства.

Все это предопределило выбор как объекта, так и предмета данного исследования, формализацию его цели, которой является решение проблемы, связанной с формированием финансового механизма интенсификации инновационных процессов в регионе.

Объектом исследования является инновационное производство, протекающее в субъектах промышленного комплекса региона, управление которым направлено на интенсификацию.

В общем смысле интенсификация инновационного производства - это приводящий к существенным социальным изменениям процесс подготовки и постепенного осуществления инновационных изменений в сфере экономики, социально-общественной и политической жизни и других сферах деятельности человека на сопутствующих уровнях в виде сменяющихся фаз жизненного цикла в сторону уменьшения [Павлов, 2009].

Рассматривая процесс интенсификации инновационного производства, мы имеем дело с тремя отличными, нетождественными в своей сущности видами экономии: временем, финансами и производственными ресурсами. В зависимости от того, какой ресурс рассматривают в качестве объекта интенсификации (человеческий, информационный, технический, коммуникационный или финансовый), выделяют направление или формы

\footnotetext{
${ }^{17}$ Канд. эконом. наук, доцент Белгородского государственного университета.
} 
интенсификации инновационного производства.

В условиях, когда региональные предприятия не имеют собственных средств для финансирования инноваций, остро встает вопрос о формировании механизмов финансирования инновационного производства.

В стабильных экономических условиях необходимые механизмы финансирования инновационного производства обеспечиваются автоматически. Однако в рамках финансового кризиса подобные условия должны создаваться государством. Сюда, в первую очередь, необходимо отнести законодательное оформление инновационной деятельности, а также закрепление на уровне нормативно-правовых актов характера воздействия финансовых рычагов на интенсификацию инновационного производства. Решающая роль здесь принадлежит рычагам косвенного стимулирования: налоговым льготам, кредиту, процентным платежам за кредит, страхованию, амортизационным отчислениям и т.д. [Иода, 2008]. При этом степень стимулирующего влияния каждого из перечисленных типов финансовых рычагов различна, она во многом зависит от целей и задач инновационного развития. Состав наиболее предпочтительных мер обеспечения интенсификации инновационного производства для каждого этапа инновационного процесса приведен в таблице 1.

Таблица 1

Состав наиболее предпочтительных мер обеспечения интенсификации инновационного производства на региональном уровне

\begin{tabular}{|c|c|c|c|}
\hline Виды деятельности & $\begin{array}{c}\text { Результаты } \\
\text { деятельности }\end{array}$ & $\begin{array}{c}\text { Этапы } \\
\text { инновационного } \\
\text { процесса } \\
\end{array}$ & $\begin{array}{c}\text { Меры по обеспечению } \\
\text { интенсификации } \\
\text { инновационного производства }\end{array}$ \\
\hline Фундаментальные & $\begin{array}{lr}\text { Новые } \\
\text { знания, } \\
\text { использование } \\
\text { которых r } \\
\text { регламентировано }\end{array}$ & \multirow{2}{*}{$\begin{array}{l}\text { Научно- } \\
\text { исследовательские } \\
\text { работы }\end{array}$} & 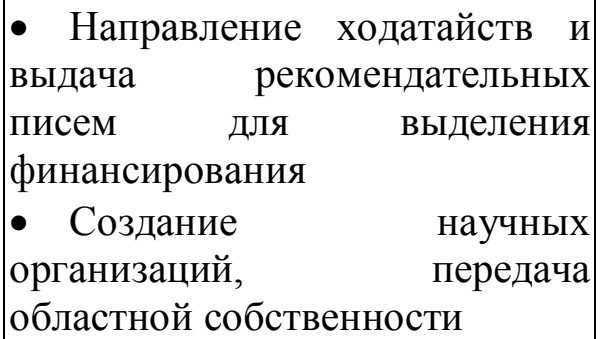 \\
\hline Прикладные & \begin{tabular}{|l|} 
Новые знания, \\
необходимые для \\
проведения \\
конкретной \\
опытно- \\
конструкторской \\
работы \\
\end{tabular} & & 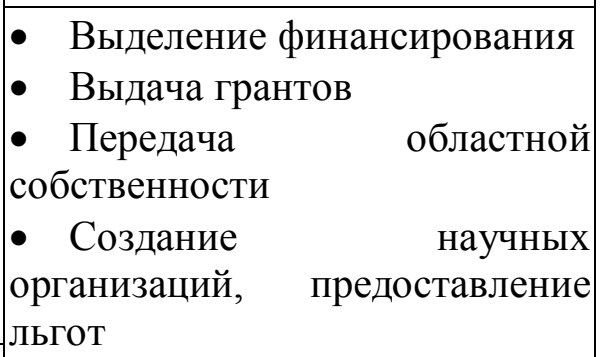 \\
\hline Технологические & $\begin{array}{l}\text { Опытный образец } \\
\text { Образец, удобный } \\
\text { для использования } \\
\text { в коммерческих } \\
\text { целях }\end{array}$ & $\begin{array}{l}\text { Опытно- } \\
\text { конструкторские } \\
\text { работы }\end{array}$ & $\begin{array}{l}\text { - } \text { Приобретение научно- } \\
\text { технической продукции } \\
\text { - } \text { Направление ходатайств } \\
\text { - } \text { Организация участия в } \\
\text { конкурсах } \\
\text { - } \quad \text { Выдача рекомендательных } \\
\text { писем } \\
\text { - } \quad \text { Организация рекламы } \\
\end{array}$ \\
\hline $\begin{array}{l}\text { Производство } \\
\text { (деятельность) }\end{array}$ & $\begin{array}{l}\text { Техническое } \\
\text { измерение } \\
\text { конкретного } \\
\text { производства } \\
\text { (организация }\end{array}$ & $\mid \begin{array}{l}\text { Массовый выпуск } \\
\text { инновационной } \\
\text { продукции }\end{array}$ & $\mid \begin{array}{ll}\bullet \quad \text { Выделение } & \text { частичного } \\
\text { финансирования } & \\
\bullet \quad \text { Предоставление } & \text { бюджетных } \\
\text { ссуд } & \end{array}$ \\
\hline
\end{tabular}




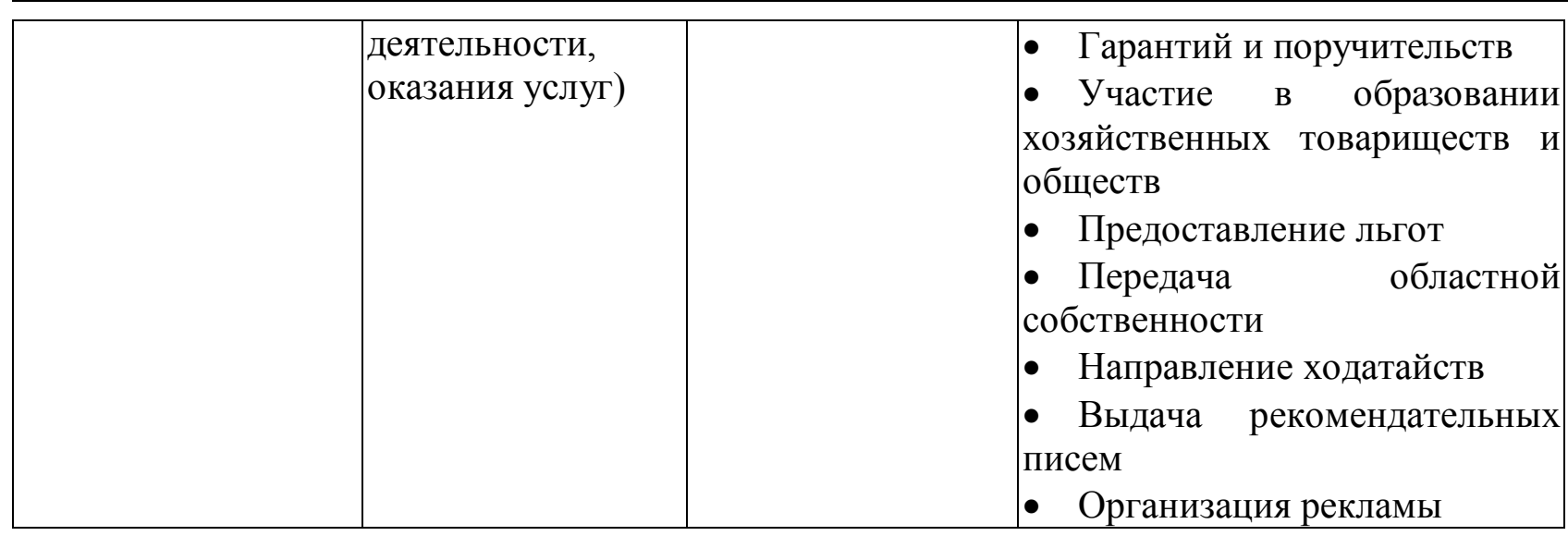

Кроме перечисленных мер, финансовый механизм обеспечения интенсификации инновационного производства включает порядок принятия и решения о финансировании проекта.

Для принятия решений при выборе и реализации инновационных проектов и программ используют традиционные подходы:

- анализ внешней и внутренней среды;

- формулировка целей, приоритетов и критериев инновационного проекта;

- создание альтернативных вариантов инновационных проектов;

- оценка их социально-экономической эффективности;

- выбор лучшего из вариантов.

Усовершенствованный финансовый механизм обеспечения интенсификации региональных инновационных проектов и программ устанавливает новые, более рациональные связи между всеми его элементами.

При этом он включает в себя весь процесс разработки и принятия данных проектов и программ:

- формирование инновационного предложения и инновационного спроса потенциальными потребителями и заказчиками инноваций;

- инициацию инновации;

- рассмотрение инновационного предложения в отраслевой рабочей группе департамента экономического развития региона;

- разработку инновационного проекта или программы и оценку его социальноэкономической эффективности;

- рассмотрение проекта губернатором или председателем правительства региона для принятия решения о финансировании;

- представление одобренного проекта в законодательный орган власти и внесение стоимости проекта в консолидированный бюджет.

Законодательными и исполнительными органами региона создается система управления, мониторинга и оценки результатов внедряемого проекта, связанная обратными связями со всеми предшествующими этапами процесса [Еремеев, 2009]. Финансовый механизм обеспечения интенсификации инновационного производства в регионе представлен на рисунке 1 . 


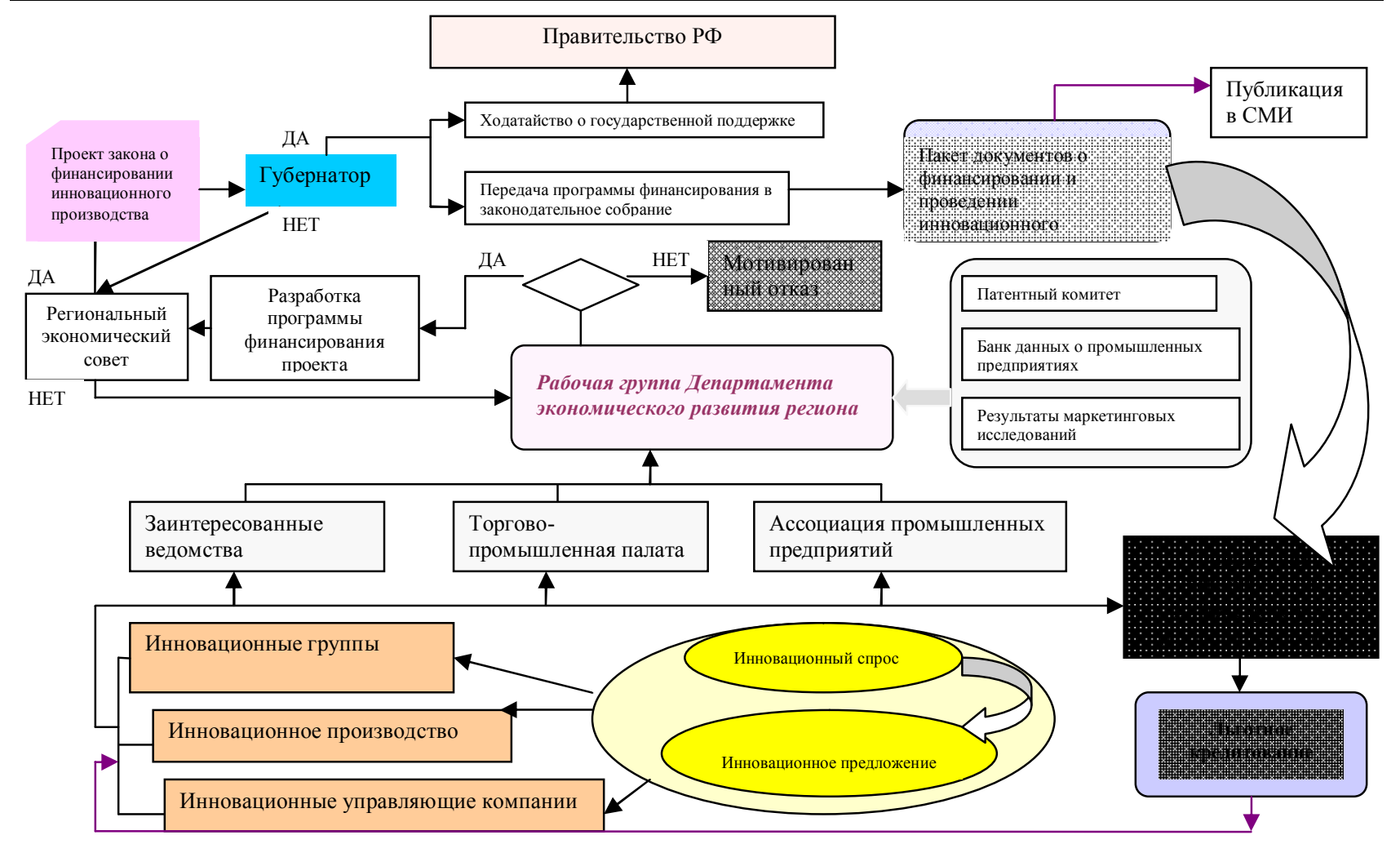

Рисунок 1. Финансовый механизм обеспечения интенсификации инновационного производства

Данный финансовый механизм включает в себя следующую последовательность действий:

1. На основе инновационного спроса и (или) инновационного предложения создается инновационный проект на предприятиях, в организациях, инновационных группах и компаниях.

2. Разработанный инновационный проект направляется с целью дальнейшей финансовой поддержки в торгово-промышленную палату, ассоциацию промышленников и предпринимателей, иные заинтересованные ведомства и непосредственно в кредитные учреждения (венчурные и инвестиционные фонды). Если кредитные учреждения выделяют средства на льготное финансирование инновационного проекта, то цикл замыкается. В случае отказа вышеперечисленные организации и ведомства передают инновационные наработки со своими комментариями в отраслевую рабочую группу департамента экономического развития региона.

3. Данная рабочая группа рассматривает все предложения и принимает решение о дальнейшей судьбе программы, используя для этого патентную информацию, банк данных о промышленных мощностях и результаты маркетинговых исследований. В случае когда рассматриваемый инновационный проект неактуален, рабочая группа оформляет мотивированный отказ (стрелка «НЕТ»). Если реализация проекта принесет прибыль, то он направляется в региональный экономический совет (стрелка «ДА» и далее).

4. Региональный экономический совет в случае выявлений недостатков и ошибок направляет всю документацию обратно в комитет экономики и развития для последующей доработки (стрелка «НЕТ»), при положительном исходе разрабатывает пакет документов «О финансировании инновационного проекта» и передает его на рассмотрение губернатору (стрелка «ДА» и далее).

5. Если губернатор не согласен с проектом закона, проект направляется на доработку обратно - в региональный экономический совет. Если губернатор принимает решение о том, что региональная казна не справится с финансированием программы, подготавливается ходатайство с просьбой о государственной поддержке и направляется в Правительство РФ 
(стрелка «ИЛИ» и далее). Если же финансирование возможно в полном объеме за счет региона, то уже одобренный пакет документов «О финансировании инновационного проекта» направляется в законодательное собрание региона.

6. Если проект закона не принимается, он направляется обратно губернатору (стрелка «НЕТ»). В случае принятия закона с учетом внесения соответствующих поправок и дополнений, руководствуясь законом региона «Об осуществлении научной, научнотехнической и инновационной деятельности», подписывают новый закон или пакет документов «О финансировании инновационного проекта» и для вступления в силу публикуют его в местных СМИ. Новый закон должен содержать необходимые меры, предусматривающие предоставление льготного финансирования для организаций, осуществляющих разработки в данной области. Успех интенсификации освоения инновационного производства во многом будет зависеть от гибкого взаимодействия основных факторов эффективности финансирования процессов. Это взаимодействие в результате предполагает выработку рыночных условий для выхода на внешний уровень созидательной активности, смещение приоритетов государственного регулирования в сторону системы налоговых льгот, что способствует освоению новых производств на основе венчурного капитала.

В заключение можно сделать следующие обобщения и предложения:

1. Развитие инновационного производства финансируется в основном самими предприятиями. Ограниченность их финансовых средств приводит в свою очередь к торможению инновационного развития экономики. Ресурсы же госбюджета доступны в основном для крупных предприятий. Но даже для них масштаб обеспечения бюджетными финансовыми средствами составляет не более 3-4\% от необходимых объемов.

2. Привлечение денег крупных производственных предприятий могло бы стать серьезным вкладом в решение проблемы интенсификации инновационного производства. Большая часть промышленных предприятий пока не заинтересована в финансировании научных исследований. Сдвинуть ситуацию с мертвой точки могут только очень крупные покупатели инноваций из сырьевого сектора экономики.

3. Еще одним элементом финансового механизма обеспечения интенсификации инновационного производства является участие предприятий в международных проектах. Расширение поступлений финансов из этого источника возможно с развитием сети центров трансферта технологий с участием иностранных партнеров.

4. Другой путь привлечения рыночных денег в инновационное производство - это коммерциализация инновационного проекта в части расширения масштабов выхода предприятий на рынки с готовой продукцией. Данный путь позволит уже существующим инновационным предприятиям получить дополнительные ресурсы для вывода на рынки своих новых разработок.

5. В ряде регионов создаются гарантийные структуры и фонды, которые должны решать проблемы обеспечения займов малых предприятий в банковской системе. Успешное развитие получают также лизинговые схемы закупки высокотехнологичного оборудования малыми предприятиями и зарождающийся механизм финансирования инноваций.

6. До сих пор остается редким явлением венчурное финансирование [Дворжак, 2010]. По-видимому, это связано с отсутствием сформированных потребностей в развитии венчурных подходов. Большинство российских предприятий предпочитают производить инновационные разработки самостоятельно, тогда как практика показывает, что эта функция должна выноситься вовне, т.е. надо покупать/продавать разработку, а не проводить ее своими силами - именно это становится основой венчурного подхода. Те немногие венчурные проекты, которые заканчиваются продажей созданных предприятий, показывают, что покупатели - как правило, зарубежные фирмы или инвесторы. То есть создание отечественных венчурных 
предприятий - это работа заведомо на зарубежные рынки со всеми вытекающими отсюда последствиями. Еще одно важное обстоятельство - существующие в настоящее время сложности выхода инвестора из создаваемого венчурного предприятия, и оно также не способствует развитию венчурного бизнеса. Следует, кроме того, отметить, что в последнее время во многих регионах начался процесс создания региональных венчурных фондов. В большинстве подобных случаев слово «венчурный» в названии отражает лишь модную тенденцию. По существу большинство этих структур являются фондами поддержки инновационной деятельности, нацеленными на финансирование научных исследований и не предполагающими создания новых предприятий.

\section{Список литературы}

1. Павлов К.В. Об инновациях интенсивного и экстенсивного типов // Общество и экономика. 2009. № 1. С.85-98.

2. Иода Е.В., Подколзин В.В., Кутеев И.А. Роль финансовой инфраструктуры в развитии региональной инновационной системы // Вестник ГТУ. 2008. Выпуск 5(61). С.166172.

3. Еремеев С.Г. Проблемы и инструменты территориального инновационного развития в России // Экономика и управление. Спецвыпуск. 2009. № 2/5(42). С. 34-39.

4. Дворжак И., Кочишова Я., Прохазка П. Венчурный капитал в странах Центральной и Восточной Европы // Проблемы теории и практика управления. 2010. № 5. URL: http://business.rin.ru/cgi-bin/search.pl?action= view \&num $=342231 \&$ razdel $=40 \& w=0$. Загл. с экрана. 